\title{
Analysis on the clinical and endoscopic parameters in 1247 patients with reflux esophagitis
}

\author{
Xiao Zhang, Huan Wang, Wei’an Wang, Xiaoguang Chen, Haifeng Liu* \\ Department of Gastroenterology, General Hospital of Chinese People’s Armed Police Forces, Beijing, China \\ Email: "haifengliu333@163.com
}

Received 23 November 2013; revised 26 December 2013; accepted 15 January 2014

Copyright (C) 2014 Xiao Zhang et al. This is an open access article distributed under the Creative Commons Attribution License, which permits unrestricted use, distribution, and reproduction in any medium, provided the original work is properly cited. In accordance of the Creative Commons Attribution License all Copyrights (c) 2014 are reserved for SCIRP and the owner of the intellectual property Xiao Zhang et al. All Copyright (C) 2014 are guarded by law and by SCIRP as a guardian.

\section{ABSTRACT}

Aim: To summarize and analyze the clinical and endoscopic parameters in patients with reflux esophagitis(RE). Methods: 1247 patients with RE were diagnosed in our hospital endoscopy center from September 2010 to August 2012. The general information of the patients and the relationship between endoscopic classification and concomitant diseases were analyzed. Results: According to the endoscopic findings, 1247 subjects $(4.70 \%)$ were found to have RE: $932(74.74 \%)$ males and 315 (25.26\%) females, and the male to female ratio was 2.96:1. The peak age of prevalence was 50 to $59(27.35 \%)$ which is followed by 40 to 49 $(23.10 \%)$. In this study, most of the patients had a mild degree of esophagitis representing LA-A in $60.63 \%$ and LA-B in $34.24 \%$. The antrum hyperemia was found in 291 patients with esophagitis (23.34\%), followed by antrum erosion $(\mathbf{2 0 . 1 3 \% )}$ ) and hatal hernia $(\mathbf{1 5 . 8 8 \% )})$. There is no statistically significant relevance between Helicobacter pylori infection and RE ( $P$ > 0.05), but Barrett's esophagus, duodenal ulcer, gastroesophageal tumors, a history of gastroesophageal surgery and antrum hyperemia were found to be associated with RE $(P<\mathbf{0 . 0 5})$. Conclusion: The prevalence rate of endoscopic $R E$ in our study was $4.70 \%$, and most patients had a mild grade esophagitis. Male, advanced age, Barrett's esophagus, duodenal ulcer, gastroesophageal tumors and a history of gastroesophageal surgery are the risk factors of esophagitis. Antrum hyperemia may reduce the severity of RE.

\section{KEYWORDS}

Reflux Esophagitis; Endoscopy; Clinical Parameters;

"Corresponding author.

\section{Antrum Hyperemia}

\section{INTRODUCTION}

Gastroesophageal reflux disease (GERD) is defined as troublesome symptoms and/or complications due to abnormal reflux of gastrointestinal contents into the esophagus [1-5]. It is often combined with esophageal mucosal injury which is called reflux esophagitis (RE). Previously, GERD was considered as a very uncommon disease in Asia, but now the disease seemed to be increasing [2,3]. RE has been classified as a typical manifestation of GERD, which has a seriously impact on the quality of the patient's life by suffering boring symptoms and diverse complications. Consequently, to further enhance the awareness of the disease and to summarize the features of epidemiology and endoscopy of RE, we conducted a retrospective analysis of 1247 patients with $\mathrm{RE}$, which was diagnosed endoscopically in our hospital.

\section{MATERIALS AND METHODS}

\subsection{Patients}

Between September 2010 and August 2012, A total of 26,508 patients underwent an upper gastrointestinal endoscopy in our hospital. Any patients who were endoscopically diagnosed as RE were included, whose demographic data, the Los Angeles (LA) classification [6,7], China (Yantai) classification [7] and complications such as Hiatal hernia, Barrett's esophagus (BE), H. pylori infection etc. were specifically recorded and statistically analyzed.

\subsection{Methods}

Endoscopic findings of RE in the lower esophagus were classified according to the Los Angeles (LA) classifica- 
tion as grades $\mathrm{A}$ to $\mathrm{D}$ (LA-A to D), and were based on the longest length of a mucosal break, and the confluence of erosion (Table 1).

Chinese (Yantai) classification [National reflux esophageal disease (inflammation) Seminar, 1999, Yantai] [8]: 0: normal esophageal mucosa (histologic changes); 1) dot or strip redness, erosion, no fusion phenomenon; 2) strip redness, erosion, and fusion, but not the full circumference; 3) extensive lesions, redness, resistance to erosion fusion was a full circumference or ulcers. LA-A, $\mathrm{B}$, and level I defined as mild grade, LA-C and level II defined as moderate grade, LA-D and level III defined as severe grade.

A hiatal hernia was defined as a distance more than 2 $\mathrm{cm}$ between the Z-line and the diaphragm. BE is a change in the distal esophageal epithelium of any length that can be recognized as columnar type mucosa at endoscopy and is confirmed to have intestinal metaplasia by biopsy of the tubular esophagus [8]. H. pylori infection was diagnosed by antral biopsy specimens for The rapid urease test.

\subsection{Statistical Analysis}

Data analysis was performed by using the t-test, chisquared test, One-way ANOVA and Pearson correlation analysis. A P value below 0.05 was considered statistically significant.

\section{RESULTS}

\subsection{The Epidemiological Features in 1247 Patients with RE}

Among 26,508 patients from September 2010 to August 2012, 1247 patients were diagnosed as RE, and the overall prevalence was $4.70 \%$ (Chart 1). The esophagitis is more prevalent among male than female $(74.74 \%$ in male and $25.26 \%$ in female), with the male: female ratio being 2.96:1. The age of the patients range from 15 to 92 , The mean age is $51.61 \pm 14.32$ (Table 2).

\subsection{The Relationship between Gender and Age}

Among the 1247 cases of reflux esophagitis, the occur-

Table 1. The Los Angeles classification of oesophagitis.

\begin{tabular}{|c|c|}
\hline Grade A & $\begin{array}{l}\text { One (or more) mucosal break no longer than } 5 \mathrm{~mm} \text {, that } \\
\text { does not extend between the tops of two mucosal folds }\end{array}$ \\
\hline Grade B & $\begin{array}{l}\text { One (or more) mucosal break more than } 5 \mathrm{~mm} \text { long that } \\
\text { does not extend between the tops of two mucosal folds }\end{array}$ \\
\hline Grade C & $\begin{array}{l}\text { One (or more) mucosal break that is continuous } \\
\text { between the tops of two or more mucosal folds but } \\
\text { which involves less than } 75 \% \text { of the circumference }\end{array}$ \\
\hline Grade D & $\begin{array}{l}\text { One (or more) mucosal break which involves at least } \\
75 \% \text { of the oesophageal circumference }\end{array}$ \\
\hline
\end{tabular}

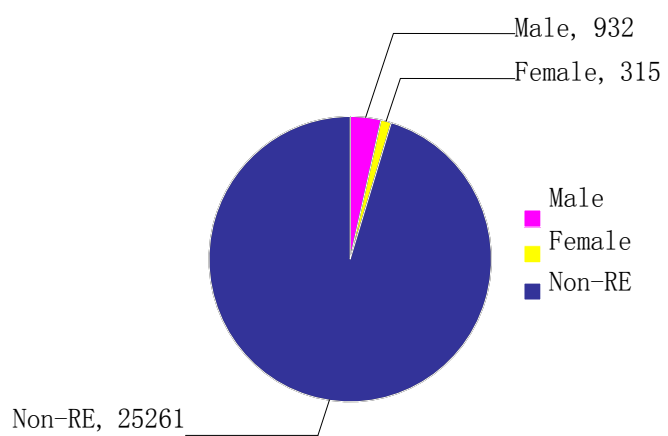

Chart 1. The relationship between the detection rate and gender of $\mathrm{RE}$.

Table 2. The gender, age and the LA classification of RE.

\begin{tabular}{cccccc}
\hline & LA-A & LA-B & LA-C & LA-D & No. \\
\hline No. & 756 & 427 & 56 & 8 & 1247 \\
Sex & & & & & \\
Male & 534 & 347 & 44 & 7 & 932 \\
Female & 222 & 80 & 12 & 1 & 315 \\
Male: & 2.41 & 4.34 & 3.67 & 7 & 2.96 \\
Female & 50.16 & 52.66 & 61.98 & 58.00 & 51.61 \\
Mean & \pm 14.02 & \pm 14.36 & \pm 14.33 & \pm 15.67 & \pm 14.32 \\
age & & Age group(year) & & \\
& 4 & 1 & 0 & 0 & 5 \\
$<20$ & 58 & 29 & 0 & 0 & 87 \\
$20-29$ & 58 & 49 & 4 & 0 & 170 \\
$30-39$ & 117 & 99 & 10 & 4 & 288 \\
$40-49$ & 175 & 122 & 10 & 1 & 341 \\
$50-59$ & 208 & 67 & 9 & 1 & 197 \\
$60-69$ & 120 & 47 & 20 & 0 & 133 \\
$70-79$ & 66 & 13 & 3 & 2 & 26 \\
$\geq 80$ & 8 & & & &
\end{tabular}

ring age of esophagitis peaked during the 50 and 60 (341 cases, $27.35 \%$ ), followed by the 40 and 50 (288 cases, $23.10 \%$ ) (Table 2). There were more male than female patients with esophagitis, the average age was significantly lower in male patients with esophagitis than in female (50.08 \pm 14.00 vs $56.14 \pm 14.31, \mathrm{P}<0.01)$ (Table 2$)$. The male to female ratio of the 30 and 40 was higher in patients with reflux esophagitis (147 cases in male and 23 cases in female, the male: female ratio was 6.39:1), followed by the 40 and 50 (236 cases in male and 52 cases in female, the male: female ratio was 4.54:1) $(\mathrm{P}<$ 0.01) (Table 3).

\subsection{The Relationship between Age and Endoscopy Classification}

According to either the (LA) classification or China 
(Yantai) trial classification, most patients were classified as mild grade, accounting for $94.87 \%$ (60.63\% in LA-A and $34.24 \%$ in LA-B). The moderate and severe grade merely made up 5.13\% (4.49\% in LA-C and $0.64 \%$ in LA-D) (Figure 1). The age distribution in patients with RE and the severity of esophagitis were positively correlated ( $\mathrm{P}<0.01$ ) (Table 4$)$. The average age in patients of LA-C group was $61.98 \pm 14.33$ years, which significantly higher than the other $(\mathrm{P}<0.01)$ (Table 4$)$.

\subsection{The Relationship between Gender and Endoscopy Classification}

According to the statistical results, the male to female ratio of the LA-D group was higher (seven cases in male and one case in female, the male: female ratio was $7: 1$ ), followed by the LA-B group (347 cases in male and 80

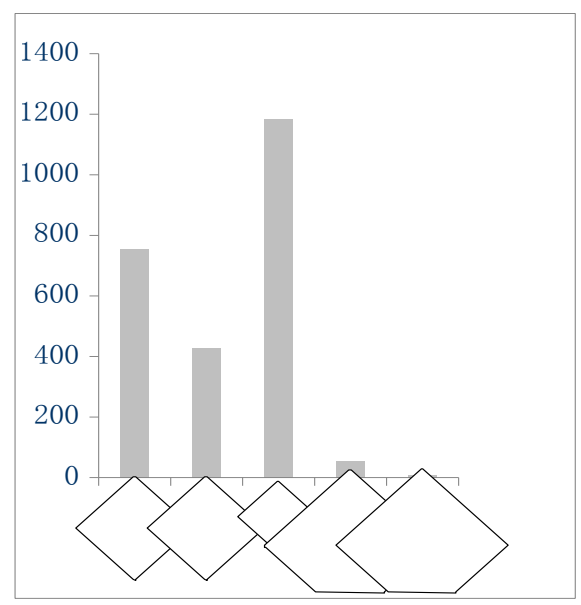

Figure 1. The LA classification and China (Yantai) trial classification.

Table 3. The relationship between gender and age.

\begin{tabular}{ccccccccc}
\hline & $<20$ & $20-29$ & $30-39$ & $40-49$ & $50-59$ & $60-69$ & $70-79$ & $\geq 80$ \\
\hline Male & 3 & 71 & 147 & 236 & 250 & 128 & 78 & 19 \\
Female & 2 & 16 & 23 & 52 & 91 & 69 & 55 & 7 \\
$\begin{array}{c}\text { Male: } \\
\text { Female }\end{array}$ & 1.5 & 4.44 & 6.39 & 4.54 & 2.75 & 1.86 & 1.42 & 2.71 \\
\hline
\end{tabular}

Table 4. The relationship between the classification and age.

\begin{tabular}{cccc}
\hline LA classification & No. & Mean age & P value \\
\hline LA-A & 756 & $50.16 \pm 14.02$ & \\
LA-B & 427 & $52.66 \pm 14.36$ & $0.009 \mathrm{a}$ \\
LA-C & 56 & $61.98 \pm 14.33$ & $<0.01 \mathrm{a}$ \\
LA-D & 8 & $58.00 \pm 15.67$ & 0.114 \\
\hline
\end{tabular}

$\mathrm{P}^{\mathrm{a}}<0.01$ versus other groups. cases in female, the male: female ratio was 4.34:1) $(\mathrm{P}<$ 0.01) (Table 2). Moreover, male patients with esophagitis are more serious than that of female, especially male patients in the LA-D group.

\subsection{Reflux Esophagitis and $H$. pylori Infection}

Among the 1247 cases of reflux esophagitis patients, there were 332 cases underwent the endoscopic rapid urease test, and the positive rate of $H$. pylori infection is $61.14 \%$. However, $H$. pylori infection has no correlation with RE ( $\mathrm{P}>0.05)$.

\subsection{The Relationship between Esophagitis and Concomitant Disease}

Among the 1247 patients with RE, 291 patients (23.34\%) had an antrum hyperemia, followed by antrum erosion (20.13\%) and hiatal hernia (15.88\%). Additional endoscopic findings reported in the patients with RE were duodenitis (9.54\%), bile reflux (9.30\%) and duodenal ulcer $(6.50 \%)$, etc. (Table 5). It is found that there is a positive correlation between the severity of esophagitis and the existence of Barrett's esophagus, duodenal ulcer, gastroesophageal tumors, and the history of gastroesophageal surgery $(\mathrm{P}<0.05)$ (Table 5$)$, while there is a negative correlation between the severity of esophagitis and the existence of the antrum hyperemia $(\mathrm{P}<0.01)$ (Table 5).

Table 5. The relationship between the classification and complications.

\begin{tabular}{|c|c|c|c|c|c|c|}
\hline & LA-A & LA-B & LA-C & LA-D & No. & $\mathrm{P}$ value \\
\hline Hiatal hernia & 113 & 68 & 14 & 3 & 198 & 0.141 \\
\hline $\mathrm{BE}$ & 6 & 7 & 2 & 1 & 16 & $0.026 a$ \\
\hline Antrum hyperemia & 201 & 84 & 6 & 0 & 291 & $<0.01 \mathrm{~b}$ \\
\hline Antrum erosion & 150 & 92 & 8 & 1 & 251 & 0.941 \\
\hline Fundic hyperemia & 34 & 24 & 2 & 0 & 60 & 0.628 \\
\hline Fundic erosion & 10 & 10 & 0 & 0 & 20 & 0.464 \\
\hline Duodenitis & 72 & 45 & 2 & 0 & 119 & 0.772 \\
\hline Bie reflux & 72 & 36 & 7 & 1 & 116 & 0.878 \\
\hline Gastric ulcer & 18 & 10 & 4 & 2 & 34 & 0.139 \\
\hline Duodenal ulcer & 38 & 35 & 7 & 1 & 81 & $0.005 a$ \\
\hline Gastric tumor & 5 & 11 & 2 & 0 & 18 & $0.004 a$ \\
\hline Gastrectomy & 3 & 8 & 2 & 0 & 13 & $0.004 \mathrm{a}$ \\
\hline Esophageal tumor & 1 & 5 & 1 & 0 & 7 & $0.011 \mathrm{a}$ \\
\hline Esophagectomy & 7 & 10 & 7 & 0 & 24 & $<0.01 \mathrm{a}$ \\
\hline
\end{tabular}




\section{DISCUSSION}

$\mathrm{RE}$, diagnosed mainly by endoscopy, has been classified as a typical manifestation of GERD, which seriously affects the quality of life of patients [9-11]. GERD is a common disease with reported incidence rate being $10 \%$ - 22\% [12,13] in the United States and Western Europe [14], endoscopy-based studies also show a prevalence of erosive esophagitis from $9 \%$ to $23 \%$ in these countries $[13,15]$. Whereas, the incidence rate in Asian countries is relatively low [16]. The reason for this phenomenon may be related to the differences in ethnicity, geography, diet etc.

In recent years, reported prevalence of RE is $3.85 \%$ $8.39 \%[17,18]$ in China, which is a significant increase compared with 10 years ago $(2.0 \%-6.3 \%)$ [18-21]. This increase has been attributed to changes in dietary preference, an increase in the aging population, and technical developments in endoscopic examination. This study shows that RE detection rate was $4.70 \%$ which is more often discovered in male than female, consistent with other studies reported [22]. The mean age of this disease was $51.61 \pm 14.32$ years and peak age 50 - 59. In the group from 30 to 39 , the high prevalence in male is statistically significant. The reason to this phenomenon may be as follows: the higher mental pressure, the heavier working burden and more risk factor such as tobacco, alcohol, coffee, tea and other bad habits.

According to the result, most patients are endoscopically classified as mild grade, either according to the (LA) classification or Yantai classification, accounting for $94.87 \%$, while the moderate and severe grade merely take up $5.13 \%$, which shows that the China (Yantai) classification and LA classification are equally effective. According to other studies, in patients of LA-A and LA-B groups, changes in esophageal motility and response to PPI treatment are similar. So, we consider that LA-A and LA-B should be merged into the same level. Therefore, I believe China (Yantai) classification is more conducive to clinical practice. Meanwhile, There is a positive correlation trend between the age and the severity which is especially the case for the LA-C group with average age being $61.98 \pm 14.33$ years old, suggesting the aging may be a risk factor $[23,24]$.

It has been confirmed that $H$. pylori infection has a very close relationship with such disease as chronic gastritis, peptic ulcer, gastric cancer, primary malignant lymphoma, while the relationship between $H$. pylori infection and reflux esophagitis is still controversial. In this study, a total of 203 patients (61.14\%) among 332 patients have a positive result when receiving the rapid urease test, which, while is relatively higher compared with other studies [25], has no statistical significance. Some domestic study has shown similar result, but further large-scale clinical studies need to be done to give the satisfactory conclusion.

Endoscopically, there are a lot of concurrent dis- eases with $\mathrm{RE}$, in which antrum hyperemia account for the most (23.34\%), followed by antrum erosion (20.13\%) and hiatal hernia (15.88\%). It is found that there is a positive correlation between the severity of RE and the existence of Barrett's esophagus, duodenal ulcer, gastroesophageal tumors, and the history of gastroesophageal surgery, while there is a negative correlation between the the severity of RE and the existence of the antrum hyperemia. However, the reason is not clear.

\section{CONCLUSION}

Reflux esophagitis is a common disease mostly suffered by middle-aged male between 40 and 59. Most patients are endoscopically classified as mild grade and it may get advanced because of aging. $H$. pylori infection is not statistically related with the disease, and patients concurrently with antrum hyperemia are less likely to have a severe RE, while further studies are needed for this.

\section{REFERENCES}

[1] Vakil, N., Van Zanten, S.V., Kahrilas, P., et al. (2006) The Montreal definition and classification of gastroesophageal reflux disease: A global evidence-based consensus. American Journal of Gastroenterology, 101, 19001920.

http://dx.doi.org/10.1111/j.1572-0241.2006.00630.x

[2] Jung, H.-K. (2011) Epidemiology of gastroesophageal reflux disease in Asia: A systematic review. Journal of Neurogastroenterology and Motility, 17, 14-27. http://dx.doi.org/10.5056/jnm.2011.17.1.14

[3] Wang, P.-C., Hsu, C.-S., Tseng, T.-C., et al. (2012) Male sex, hiatus hernia, and Helicobacter pylori infection associated with asymptomatic erosive esophagitis. Journal of Gastroenterology and Hepatology, 27, 586-591. http://dx.doi.org/10.1111/j.1440-1746.2011.06881.x

[4] Shim, K.-N., Hong, S.J., Sung, J.K., et al. (2009) Clinical spectrum of reflux esophagitis among 25,536 Koreans who underwent a health check-up: A nationwide multicenter prospective, endoscopy-based study. Journal of Gastroenterology and Hepatology, 43, 632-638. http://dx.doi.org/10.1097/MCG.0b013e3181855055

[5] Kahrilas, P.J. and Boeckxstaens, G. (2012) Failure of reflux inhibitors in clinical trials: Bad drugs or wrong patients? Gut, 61, 1501-1509. http://dx.doi.org/10.1136/gutjnl-2011-301898

[6] Armstrong, D., Bennett, J.R., Blum, A.L., et al. (1996) The endoscopic assessment of esophagitis: A progress report on observer agreement. Gastroenterology, 111, 8592. http://dx.doi.org/10.1053/gast.1996.v111.pm8698230

[7] Miwa, H., Yokoyama, T., Hori, K., et al. (2008) Interobserver agreement in endoscopic evaluation of reflux esophagitis using a modified Los Angeles classification incorporating grades $\mathrm{N}$ and $\mathrm{M}$ : A validation study in a co- 
hort of Japanese endoscopists. Diseases of the Esophagus, 21, 355-363.

http://dx.doi.org/10.1111/j.1442-2050.2007.00788.x

[8] Chinese Medical Association Society for Gastrointestinal Endoscopy (2000) Diagnosis and treatments of reflux esophagitis disease (inflammation) (Trial). Journal of Internal Medicine, 39, 2101.

[9] Liu, H.F. and Wang, W.A. (2009) Gastroesophageal reflux disease. Beijing Scientific and Technical Documents Publishing House, Beijing, 92-93.

[10] Fass, R. (2012) Therapeutic options for refractory gastroesophageal reflux disease. Journal of Gastroenterology and Hepatology, 27, 3-7. http://dx.doi.org/10.1111/j.1440-1746.2012.07064.x

[11] Zerbib, F. (2010) Medical treatment of GORD. Emerging therapeutic targets and concepts. Best Practice \& Research Clinical Gastroenterology, 24, 937-946. http://dx.doi.org/10.1016/j.bpg.2010.08.009

[12] Dent, J., El-Serag, H.B., Wallander, M.A., et al. (2005) Epidemiology of gastro-oesophageal reflux disease: A systematic review. Gut, 54, 710-717. http://dx.doi.org/10.1136/gut.2004.051821

[13] El-Serag, H.B., Graham, D.Y., Satia, J.A., et al. (2005) Obesity is an independent risk factor for GERD symptoms and erosive esophagitis. American Journal of Gastroenterology, 100, 1243-1250. http://dx.doi.org/10.1111/j.1572-0241.2005.41703.x

[14] Yuksel, E.S. and Vaezi, M.F. (2012) New developments in extraesophageal reflux disease. Gastroenterology \& Hepatology, 8, 590-599.

[15] Ronkainen, J., Aro, P., Storskrubb, T., et al. (2005) High prevalence of gastroesophageal reflux symptoms and esophagitis with or without symptoms in the general adult Swedish population: A Kalixanda study report. Scandinavian Journal of Gastroenterology, 40, 275-285. http://dx.doi.org/10.1080/00365520510011579

[16] Kim, N., Lee, S.W., Cho, S.I., et al. (2008) The prevalence of and risk factors for erosive oesophagitis and non-erosive reflux disease: A nationwide multicentre prospective study in Korea. Alimentary Pharmacology \& Therapeutics, 27, 173-185.

http://dx.doi.org/10.1111/j.1365-2036.2007.03561.x

[17] Wang, F. and Fan, Y.J. et al. (2007) Clinical analysis of 4311 patients with reflux esophagitis. Zhengzhou University (Medical Sciences), 42, 1114-1116.

[18] Goh, K.-L. (2011) Gastroesophageal reflux disease in Asia: A historical perspective and present challenges. Gastroenterology and Hepatology, 26, 2-10.

[19] Yang, X.M., Shen, H. and Ma, S.H. (2005) Analysis of reflux esophagitis and factors correlated with it on endoscopic examination. China Journal of Endoscopy, 11, 265-267.

[20] Choi, J.Y., Jung, H.-K., Song, E.M., et al. (2013) Determinants of symptoms in gastroesophageal reflux disease: Nonerosive reflux disease, symptomatic, and silent erosive reflux disease. European Journal of Gastroenterology \& Hepatology, 25, 764-771.

[21] Miwa, H., Takubo, K., Shimatani, T., et al. (2013) Histology of symptomatic gastroesophageal reflux disease: Is it predictive of response to proton pump inhibitors? Journal of Gastroenterology and Hepatology, 28, 479487. http://dx.doi.org/10.1111/j.1440-1746.2012.07266.x

[22] Zhu, Z.-J. (2011) Clinical and endoscopic features of 767 cases with reflux esophatitis. China Coal Industry Medicine, 14, 1661-1662.

[23] Becher, A. and Den, J. (2011) Systematic review: Ageing and gastro-oesophageal reflux disease symptoms, oesophageal function and reflux oesophagitis. Aliment Pharmacol Ther, 33, 442-454. http://dx.doi.org/10.1111/j.1365-2036.2010.04542.x

[24] Wang, P.-C., Hsu, C.-S. and Tseng, T.-C. (2012) Male sex, hiatus hernia, and Helicobacter pylori infection associated with asymptomatic erosive esophagitis. Journal of Gastroenterology and Hepatology, 27, 586-591. http://dx.doi.org/10.1111/j.1440-1746.2011.06881.x

[25] Li, W., Jia, F., Zhang, S.-T., et al. (2008) Clinical and endoscopic analysis on cases of reflux esophagitis. Chinese Journal of Internal Medicine, 28, 738-741. 